\title{
Preparation of Thin Films Using Freeze Drier Alumina
}

\author{
Ronald A. Silva, Cristina F. Diniz, Marcelo M. Viana, Suzeley L. Abreu ${ }^{1,2}$, Taiane G.F. de Souza ${ }^{1,2}$, Nelcy D. S. Mohallem* \\ Laboratório de Materiais Nanoestruturados, Departamento de Química, UFMG, 31270-901 Belo Horizonte-MG, Brazil
}

Tarik D. S. Mohallem

Nanum Nanotecnologia, Belo Horizonte, MG, Brazil

(Received 01/07/2008)

\begin{abstract}
Synthesis of polymorphous of nanoparticulate alumina has been the subject of many works. The stabilization of these nanoparticles in aqueous suspensions is necessary in many technologic application and industrial products. Recently, a number of routes have been developed using various dispersants to prepare these nanoparticles dispersed in aqueous solution. In this work, nanoparticulate alumina prepared by precipitation and freezing drying was investigated as potential material for aqueous dispersion. These nanoparticles were dispersed in methylethylglycol (MEG), polyvinylalcohol (PVA) and polymethacrylate (PMA). The alumina nanoparticles and the dispersions were characterized physical-chemically and tested in the preparation of thin films.
\end{abstract}

Keywords: alumina dispersion, alumina thin films, nanoparticulate alumina

\section{INTRODUCTION}

In recent studies, different kinds of nanoparticles in form of nanosphere, nanotube, nanowire, nanorod, nanoribbon, nanoplate, among others have been developed to application in diverse technologies [1]. These nanostructures have been obtained with different shapes and sizes, high specific surface area, and consequently with high reactivity. The knowledge obtained with these studies has brought important contributions to the advance of the nanotechnology. Therefore, nanoparticle productions present many difficulties depending on the particular properties desired. The manipulation of these materials is very difficult, taking in account problems with fabrication, transport, final application and toxicity [2].

One way to manipulate this type of nanomaterial after synthesis consists in the preparation of colloidal dispersions. In that way the manipulation become easy and it is possible to prepare thin films from dispersions of low concentration, nanoabrasives from alpha-alumina disperse in high concentrations and adequate dispersions to mix in precursor pastes of refractory materials. Colloidal dispersion is systems in which particles with dimension between 1 and $1000 \mathrm{~nm}$ are dispersed in a continuous phase. This kind of system can be formed due to four interaction energies: van der Waals, electrostatic, steric and depletion interaction energies. The colloidal suspension must have appropriated physical-chemical properties to produce the final product with desired characteristics, such as transparent, adherent and homogeneous thin films, nanoabrasives or refractory material pastes.

The dispersion of alumina nanoparticles is more difficult than of the particles with size in the order of microns due to the tendency to agglomeration provoked by the high reactivity.

In this study, we produced colloidal dispersions from alumina nanoparticles prepared by precipitation and dried by lyophilisation, dispersed in water, using methylethylglycol (MEG), polyvinylalcohol (PVA) and polymethacrylate (PMA) as dispersants. The aluminas were characterized by $\mathrm{X}$-ray diffraction (XRD) and gas adsorption. The solutions

*Electronic address: nelcy@ufmg.br were characterized by nuclear magnetic resonance (NMR) and used in the preparation of thin films by dipping coating process [3-8]. The films were characterized by X-ray diffraction (XRD), energy dispersive spectroscopy (EDS) and atomic force microscopy (AFM).

\section{EXPERIMENTAL}

Aluminum nitrate hexahidratate $\left[\mathrm{Al}\left(\mathrm{NO}_{3}\right)_{3} \cdot 6 \mathrm{H}_{2} \mathrm{O}\right]$ and ammonia solution were used as starting reactants materials. $\mathrm{Al}\left(\mathrm{NO}_{3}\right)_{3} \cdot 6 \mathrm{H}_{2} \mathrm{O}$ were dissolved in deionized water and the ammonia solution was added to the solution during agitation. The obtained white precipitate was washed with deionized water to remove impurities. The materials were submitted to freezing drying process generating particles with boehmite phase that was calcined at $800^{\circ} \mathrm{C}$ to become alpha alumina.

The aluminas were analyzed by X-ray diffractometry (Rigaku, Geigerflex 3034) with $\mathrm{CuK} \alpha$ radiation, $40 \mathrm{kV}$ and $30 \mathrm{~mA}$, time constant of $0.5 \mathrm{~s}$ and crystal graphite monochromator. Crystallite size was determined by Scherrer equation $(\mathrm{D}=0.9 \lambda / \beta \cos \theta$, where $\mathrm{D}$ is the crystallite diameter, $\lambda$ is the radiation wavelength and $\theta$ the incidence angle).

Sample textural characteristics were determined through nitrogen gas adsorption (Autosorb - Quantachrome Nova 1200) at liquid nitrogen temperature. Nitrogen gas was used with a 22-point adsorption-desorption cycle. The samples were outgassed at $200{ }^{\circ} \mathrm{C}$ for $3 \mathrm{~h}$ before each analysis. Specific surface areas (SSA), average particle size (d) were obtained by the application of the Brunauer-Emmett-Teller (BET) equation [9]. The average particle size was evaluated using the equation: $d(n m)=6 / S \cdot \rho$, where 6 is the form factor for spherical or cubic particles, $S$ is the superficial area in $\mathrm{m}^{2} \mathrm{~g}^{-1}$ and $\rho$ is the true density in $\mathrm{g} \mathrm{cm}^{-3}$. The true densities were evaluated by helium picnometry (Quantachrome).

The boehmite, gamma-alumina and alpha-alumina prepared were dispersed in water using methylethylglycol (MEG), polyvinylalcohol (PVA) and polymethacrylate (PMA) as dispersants. Viscosity and density of the colloidal alumina dispersions were measured using an Ostwald viscometer and a glass pycnometer. Nuclear Magnetic Resonance $\left(\mathrm{NMR}{ }^{27} \mathrm{Al}\right)$ spectra were obtained by a equipment Bruker Avance DRX 400 to identify the aluminas in suspen- 
sion.

The films were prepared by dip-coating process in glass substrates, using solutions prepared with boehmite, gamma and alpha-alumina with viscosity between 3 and $6 \mathrm{cp}$, and $\mathrm{pH}$ of $\sim 3$. The withdrawal speed was of $8 \mathrm{~mm} / \mathrm{sec}$, and the obtained wet films were dried in air for $30 \mathrm{~min}$ and thermally treated for 15 min at $400{ }^{\circ} \mathrm{C}$.

The particle size distribution and roughness of the films were evaluated by atomic force microscopy (Nanoscope II and a Dimension 3000, Digital Instruments) equipped with an extended modulus for phase imaging. The images were generated through the intermittent contact mode, using a silicon probe tip with $5 \mathrm{~nm}$ of curvature radius.

\section{RESULTS AND DISCUSSION}

X-ray diffractograms of the aluminas prepared at different temperatures are showed in the Figure 1. With the increase in the temperature, the crystalline boehmite formed by freeze drying lost water, and its structure is annihilated originating intermediary alumina ( $\gamma$-alumina). The structure of the intermediary alumina self-organizes with the increasing in the temperature forming the $\alpha$-alumina at $1200{ }^{\circ} \mathrm{C}$.
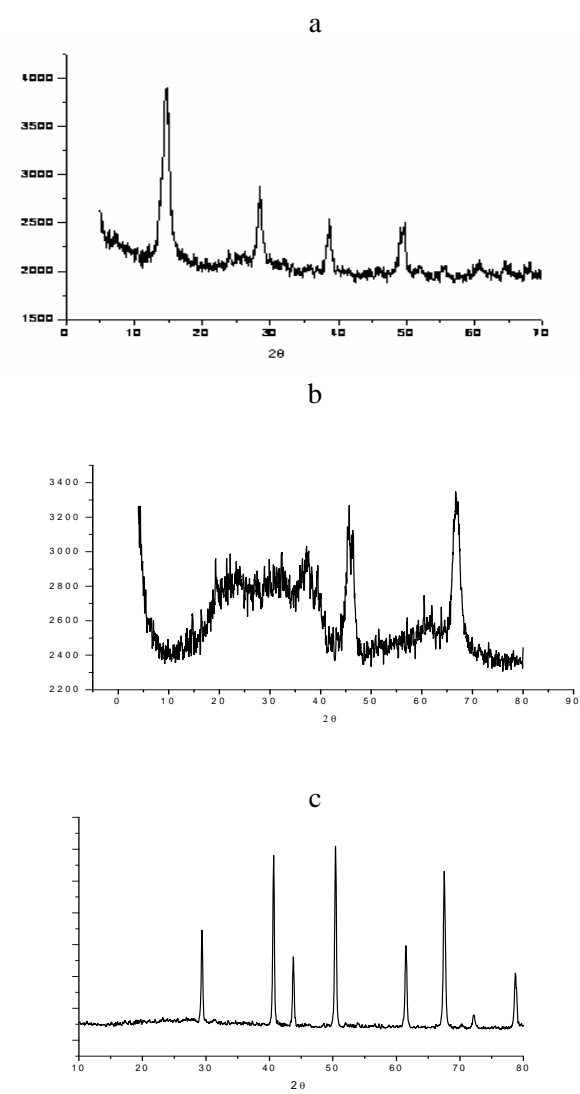

FIG. 1: X-ray diffraction patterns of: a) $\mathrm{Al}_{2} \mathrm{O}_{3} \cdot \mathrm{H}_{2} \mathrm{O}$ prepared by freezer drying, b) gamma- $\mathrm{Al}_{2} \mathrm{O}_{3}$ prepared at $800^{\circ} \mathrm{C}$ and c) alpha$\mathrm{Al}_{2} \mathrm{O}_{3}$ prepared at $1200{ }^{\circ} \mathrm{C}$.

The aluminas prepared by freezer drying were nanoparticulate in all temperatures of thermal treatment. Table 1 shows the alumina textural characteristics obtained by gas adsorp-
TABLE 1 - Textural characteristics of aluminas prepared by freezer drying and calcined at different temperatures.

\begin{tabular}{ccccc}
\hline $\begin{array}{c}\text { Calcination } \\
\text { temperature } \\
\left({ }^{\circ} \mathrm{C}\right)\end{array}$ & $\begin{array}{c}\rho \\
\left(\mathrm{g}^{\mathrm{c}} \mathrm{cm}^{-3}\right)\end{array}$ & $\begin{array}{c}\mathrm{SSA}_{\text {BET }} \\
\left(\mathrm{m}^{2} / \mathrm{g}\right)\end{array}$ & $\begin{array}{c}\mathrm{D} \\
(\mathrm{nm})\end{array}$ & $\begin{array}{c}\mathrm{d}_{\mathrm{P}} \\
(\mathrm{nm})\end{array}$ \\
\hline $\begin{array}{c}\text { As-prepared } \\
800\end{array}$ & 2.3 & 289 & 8 & 9 \\
1200 & 3.6 & 193 & 9 & 9 \\
\hline
\end{tabular}

SSA: specific surface area, $\mathrm{d}_{\mathrm{p}}$ : average particle size, $\rho$ : true density, D: average crystallite size.
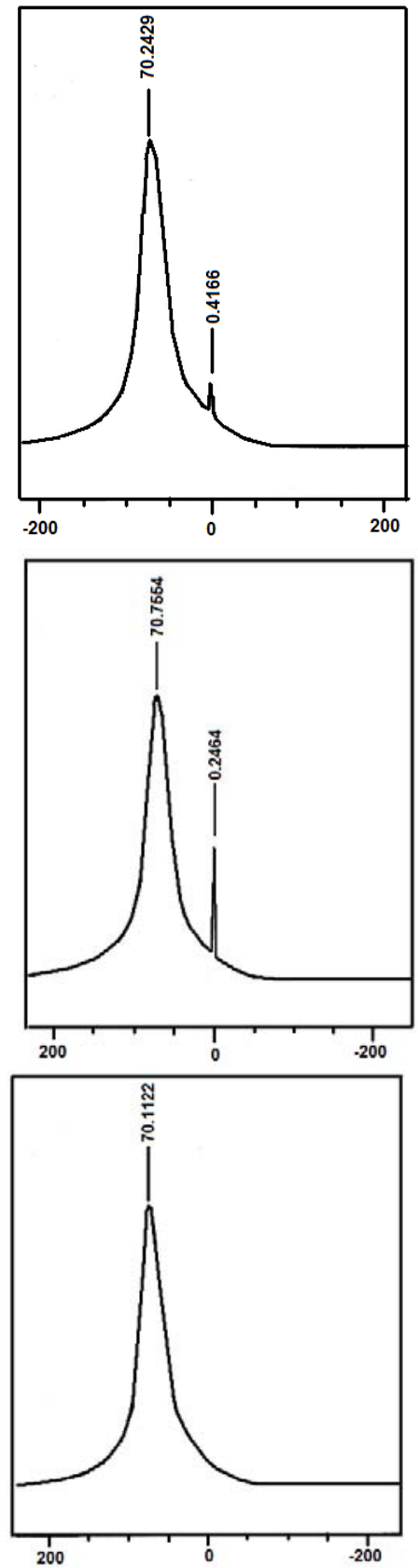

FIG. 2: NMR- ${ }^{27} \mathrm{Al}$ spectra of colloidal aluminas prepared with: a) boehmita, b) gamma-alumina c) alpha alumina 


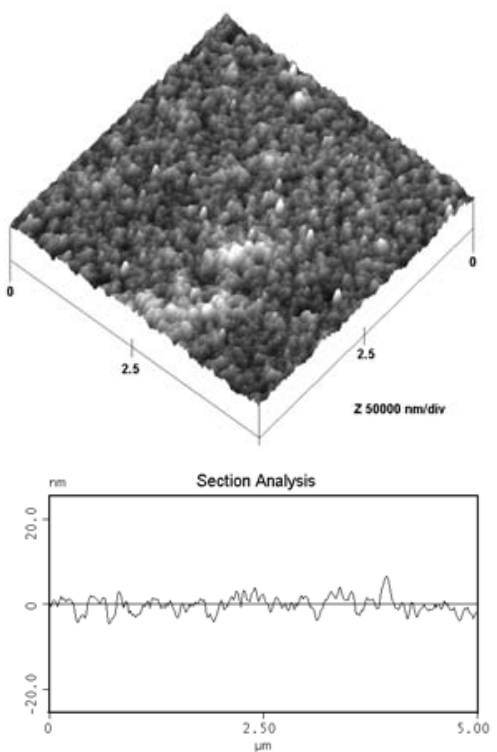

FIG. 3: a - AFM image of gamma-alumina thin film treated at $400^{\circ}$ $\mathrm{C}, \mathrm{b}$ - Line profile of gamma-alumina thin film treated at $400^{\circ} \mathrm{C}$

tion. We can observe that the as-prepared aluminas have specific surface area extremely high $\left(289 \mathrm{~m}^{2} / \mathrm{g}\right)$, whose values remained high even when heated at $1200{ }^{\circ} \mathrm{C}\left(118 \mathrm{~m}^{2} / \mathrm{g}\right)$. The average particle size almost did not change with the increase in the temperature, remaining between $9 \pm 2$ and $13 \pm 3 \mathrm{~nm}$. The average particle size measured by gas adsorption was similar to average crystallite size measured by XRD, suggesting that the particles are monodisperse.

The aluminas stabilized with all dispersants stayed stable and showed adequate properties to be used to prepare the thin films. The NMR- ${ }^{27} \mathrm{Al}$ spectra (Figure 2) show that the aluminas remained in the solution, without dissolution. The three dispersant used showed the same results.

It was not possible prepare thin films with the alphaalumina dispersion. The films obtained with the gammaalumina dispersion presented defects and cracks. The asprepared films obtained with the boehmite solution were transparent and adherent. Thermal treatments were carried out at $400^{\circ} \mathrm{C}$, without crack of the films. After thermal treatment the thin films presented gamma-phase according XRD analyses.

A typical AFM analysis (Figure $3 a$ and $3 b$ ) revealed that the obtained thin films are homogeneous with average particle size in the order of $100 \pm 8 \mathrm{~nm}$. The films are formed by crystalline nanoparticles of $\gamma-\mathrm{Al}_{2} \mathrm{O}_{3}$.

\section{CONCLUSION}

The alumina obtained were monodispersed even when prepared at high temperatures. The obtained nanoparticles were adequate to preparation of colloidal alumina systems. The colloidal boehmite had physical-chemistry properties adequate to be used in the preparation of homogeneous thin films, with average particle size in the order of $100 \pm 8 \mathrm{~nm}$.

\section{Acknowledgement}

This work was supported by CNPq and FINEP/Sebrae. The authors thank LNLS- Campinas/Brazil for AFM images.
[1] D. H. Everett, Basic Principles of Colloid Science, Royal Society of Chemistry, UK, 1992.

[2] J. Cesarano and I. A. Aksay, J. Amer. Ceram. Soc. 71(12)(1988)1062.

[3] J. Brinker, Scherer, Sol-Gel Science, Academic Press, 2 nd ed. 1999.

[4] H. Schroeder, Phys. Thin Films 87 (1969).

[5] N.D. S. Mohallem, M.A.Aegeter, J. Non-Cryst. Solids, 100
(1988) 526

[6] N.D. Mohallem, L. M. Seara, App. Surf. Sci., 214 (2003)143.

[7] Q. Li and J. A. Lewis, Advanc. Mater. 15(19)(2003)1639.

[8] G. L. T. Nacimento, L. M. Seara, B. R. A. Neves and N. D. S. Mohallem, Progr. Colloid Polym. Sci 128 (2004)227.

[9] S.J. Greg, K.S.W. Sing. Adsorption, Surface Area and Porosity, 2002. 